VARIA 
ISSN: $1130-2887$

\title{
¿SE HA ABIERTO EL SISTEMA POLÍTICO COLOMBIANO? UNA EVALUACIÓN DE LOS PROCESOS DE CAMBIO
} (1970-1998)

Is it opened the Colombian political system?

An evaluation of the process changes (1970-1998)

\author{
Francisco GUTIÉRREZ SANÍN \\ Profesor del Instituto de Estudios Politicos y Relaciones Internacionales de la Universidad Nacional de Colombia.
}

BIBLID [1130-2887 (2001) 27, 189-215]

Fecha de recepción: diciembre de 2000

Fecha de aceptación y versión final: marzo de 2001

RESUMEN: A pesar de la continuidad democrática colombiana, existe una prolongada crisis de su sistema político que se refleja en varias dimensiones. Esta crisis se ha atribuido tradicionalmente a los efectos que se derivan del «cierre» del sistema político colombiano. A través del análisis de las diferentes dimensiones del «cierre político», indicando qué tipo de implicaciones tiene cada una de ellas para el sistema y cómo han evolucionado, se trata de ver si los defectos del sistema político que tradicionalmente se han atribuido a este «cierre» son en realidad causa exclusiva del mismo o bien pudieran deberse en parte a la apertura política del sistema. El paso del cierre a la apertura política tiene como consecuencia que durante un período de tiempo relativamente prolongado los indicadores de convivencia y civilidad empeoren, éste sería el caso de Colombia, donde en las últimas décadas se han dado una serie de aperturas y cierres simultáneos, siendo esta tensión entre cierre y apertura la que ha provocado avances, estancamientos y retrocesos democráticos simultaneos.

Palabras clave: Cierre, bipartidismo, desproporcionalidad, modernización, Colombia.

Abstract: In spite of colombian democratic continuity, there is a extend crisis in its political system that reflects in several aspects. This crisis has been derived traditionally from «the closing» of the colombian political system. Through the analysis and evolutions of several aspects of «political closing» and its implies on the system, it is tried to proof if they are cause of the defects of the political system. The transit from the closing to the opening can deteriorate the indicators of coexistence and public spirit, there's the case of Colombia, where in the last decades the excessives openings and closings have simultaneous advances and breaking downs in the democracy.

Key words: Closing, bipartidism, desproporcionality, modernization, Colombia. 


\section{INTRODUCCIÓN ${ }^{1}$}

Uno de los rasgos más notables de la «excepcionalidad colombiana» es la combinación de continuidad democrática con enormes dificultades para gestionar el conflicto dentro de los límites institucionales. En este sentido específico, es lícito hablar de una prolongada crisis de nuestro sistema político (Bond, Craig, Jenkins, Taylor y Schock, 1997: 561). No ha habido en las últimas cuatro décadas una ruptura institucional, quizás ni siquiera un conato realmente serio de cesura autoritaria; la otra cara de la moneda es una creciente catástrofe humanitaria, la proliferación de factores de ilegalidad y la pérdida de casi todos los monopolios estatales (de las aduanas, de los impuestos y del uso legítimo de la fuerza).

Muchos de estos males endémicos se han atribuido al cierre del sistema político. La concentración del poder en pocas manos habría provocado insatisfacción generalizada, pobre funcionamiento del aparato de justicia, bloqueos institucionales duraderos (Pizarro, 1989, 1993), exclusiones sistemáticas (Ramírez, 1990), déficits permanentes de representación (Leal, 1984), y clientelización de las prácticas políticas (Leal y Dávila, 1991), con sus secuelas de corrupción y deterioro. Todo ello se relacionaría con la violencia y la ilegalidad. Aquí tenemos una argumentación de dos tiempos (el cierre produce un conjunto de factores indeseables, los cuales a su vez precipitan la violencia), y es mejor reconocer que no tenemos las cosas claras con respecto de ninguno de los dos.

Pretendo en este texto, sin embargo, detenerme en un tema lógicamente anterior a esta clase de debates: ¿qué quiere decir cierre político en un país como Colombia? La importancia de adquirir un mínimo de claridad sobre el término es triple. Obviamente, la naturaleza y el grado del cierre son un tema de interés por derecho propio. Resalto especialmente la necesidad de llegar a dibujar un cuadro lo suficientemente claro y perfilado como para ser comparable con otros casos nacionales. Una de las consecuencias inmediatas de la universalización formal de la democracia en países periféricos y semiperiféricos es la necesidad de contar con buenos instrumentos de análisis para saber «qué tan democrática es cada democracia» ${ }^{2}$. Desde este punto de vista, el caso colombiano es particularmente interesante, ya que aquí fenómenos como las elecciones [semi]competitivas, la institución parlamentaria y la importancia de la ley y el derecho no se pueden considerar bajo ningún punto de vista como importaciones recientes. En segundo lugar, para buscar correlaciones con, por ejemplo, nuestra violencia endémica tenemos que saber qué vamos a contrastar con qué. En este terreno, claramente uno querría contar con enunciados falsificables. Continuando con el ejemplo del bipartidismo, se podría

1. Se presentan aquí resultados de la investigación «Violencia y Sistema Político» cofinanciada por Colciencias. Agradezco a LASA por su apoyo para la presentación de una versión inicial de este trabajo en marzo de 2000. También a Diana Hoyos, Mónica Pacho y Luisa Ramírez, y al resto del equipo de investigación por sus aportaciones al texto.

2. Una primera aproximación consiste en establecer listas de características, que después se pueden calificar. No me entusiasman en lo más mínimo tales «listas de mercado», entre otras cosas porque no captan un aspecto esencial: cómo se relaciona una característica con la otra. 
construir una hipótesis que estableciera una relación inversamente proporcional entre partido efectivo y homicidios políticos. La idea después podría refinarse introduciendo hiatos temporales (time lags) y efectos acumulativos. Si por el contrario, con la expresión cierre se tiene en mente la acumulación del poder político en manos de los notablatos tradicionales, el ejercicio tendría que ser completamente distinto. A propósito, me esforzaré en demostrar que la diferencia entre una y otra hipótesis es crucial a la hora de discutir sobre el caso colombiano. En tercer lugar, definir explícitamente qué significa cierre permite evadir al menos las argumentaciones y narrativas circulares más bastas. Con frecuencia, se le imputan axiomáticamente al cierre múltiples males, sin que haya manera ni de falsificar las afirmaciones a través de las cuales se construye la argumentación ni de colocarlas en un contexto comparativo. Se desearía, en cambio, un aparato explicativo que al menos no tomara por dados los temas centrales que deben animar toda la discusión. La axiomatización normativa ha creado varias áreas ciegas e impedido formular preguntas relativamente sencillas pero fundamentales. Uno podría, verbigracia, indagar si no ha sido precisamente una cierta apertura del sistema la que ha estado relacionada con la espiral de violencia. Por analogía con la tesis de Huntington sobre la modernización (1972), se podría pensar que el paso del cierre a la apertura empeora durante un período relativamente prolongado los indicadores de convivencia y civilidad. En una dirección un poco distinta, es posible que la combinación específica de cierres y aperturas, de inclusiones y exclusiones, defina la naturaleza de la dinámica del sistema, sus características (intensa o débilmente represivo) y sus efectos ${ }^{3}$. Para poder evaluar una u otra conjetura, se precisa saber si efectivamente el sistema se ha abierto o no.

Sorprendentemente, el esfuerzo que se ha dedicado a tratar de responder esta pregunta es mínimo. Además, cuando se ha abordado se han buscado las respuestas desde los resultados agregados a nivel nacional (típicamente: ¿ha habido o no renovación en el Congreso?), lo que constituye una muy buena garantía de perder varios de los aspectos más importantes e interesantes del problema. Se puede dar el caso de que los dos partidos tradicionales o las fuerzas clientelistas sigan ganando algunas elecciones, quizás incluso todas, y que al mismo tiempo en efecto el sistema se haya abierto en algún sentido (por ejemplo, a través de reformas institucionales incluyentes). En síntesis, es menester contar al menos con:

1. Una buena definición operativa de cierre-apertura del sistema político.

2. Una descripción de lo que ha sucedido durante el período en el conjunto de variables importantes (desde el punto de vista de 1).

3. Una descripción de los resultados electorales y políticos a nivel nacional, departamental y municipal.

En este artículo buscaré avanzar en las tres direcciones. En la primera parte se discuten distintas posibles acepciones de «cierre político», no como opciones alternativas

3. Defenderé algo muy parecido en este texto. 
FRANCISCO GUTIÉRREZ SANÍN

sino como dimensiones complementarias. En la segunda parte se evalúa qué ha sucedido con cada una de estas dimensiones. En esencia, concluiré que en algunos sentidos se ha avanzado pero en otros ha habido estancamiento e incluso retroceso. La tensión entre los dos movimientos ejerce un efecto de «trituradora» que más que exclusión produce democratizaciones selectivas, traumáticas y, ocasionalmente, desestabilizadoras. En la tercera y última se resumen estas «trampas democráticas» a la luz de la evidencia presentada.

\section{LAS DIMENSIONES DEL CIERRE}

La expresión «cierre del sistema político» se refiere a un conjunto de exclusiones duraderas, cuya magnitud es inversamente proporcional a la «cantidad de democracia real» existente en cada país. A la vez, especifica dos delimitaciones. Ante todo, descarta dimensiones socioeconómicas que convencionalmente podrían considerarse exógenas al sistema político. Esas dimensiones se rigen por otras lógicas y otros tiempos. Por ejemplo, en Colombia la concentración de la propiedad y los indicadores de desigualdad han mostrado históricamente niveles altos -para los estándares latinoamericanos y ciertamente mundiales-, pero incluso en ese contexto se han producido expresiones democráticas profundas (como la Constitución de 1991), que como argumentaré no se pueden reducir a lo puramente formal ${ }^{4}$. En segundo lugar, incluye todo el sistema. En particular, la vida política regional y municipal no es una función de la vida política nacional. Esto es especialmente importante en Colombia, donde buena parte de los esfuerzos reformistas más serios en las últimas dos décadas se concentraron en el intento de democratizar la esfera pública subnacional. El resultado inmediato es que una buena evaluación del grado de cierre del sistema tiene que contemplar las dinámicas relativamente autónomas que se desarrollan en cada uno de sus eslabones territoriales.

A continuación, expondré cuatro posibles acepciones de cierre político; solamente la primera se relaciona directamente con la «excepcionalidad colombiana». Las cuatro han sido discutidas profusamente por académicos en la literatura especializada, pero también por actores políticos, ingenieros institucionales y formadores de opinión. Al presentar cada una, intentaré precisar el tipo de implicaciones que tiene, con el propósito de extraer un conjunto de enunciados que sean susceptibles de ser sometidos a evaluación empírica.

4. Existe, adicionalmente, un problema técnico. El larga y mundialmente debatido tema acerca de la existencia de una relación entre desigualdad socioeconómica y grietas en la democracia (y violencia) parecería arrojar como respuesta un «sí» condicional. Pero los indicadores de desigualdad cambian muy lentamente, mientras que los de cierre-violencia están expuestos a cambios abruptos. Así que es necesario tener en cuenta los efectos de umbral en un contexto comparativo. Respecto de este tema, ver el libro clásico de POWELL (1982) y el excelente esfuerzo de actualización de KRAIN (1998). Para el caso colombiano, la casi totalidad de los análisis cuantitativos hechos por economistas adolece del desconocimiento de la literatura internacional y de cierta naïveté técnica que ya dejó de ser encantadora (si alguna vez lo fue). 
1. Cierre como bipartidismo excluyente. Muchos autores caracterizan a nuestro sistema político como «bipartidismo excluyente», que expresaría una «política del clientelismo» (Martz, 1997). Pero en realidad se trata de dos fenómenos que, aunque asociados, son distintos. Mientras que en términos de clientelismo es difícil argumentar que Colombia esté en situación distinta a la de, digamos, México, Perú, Ecuador o Paraguays, su bipartidismo sí constituye en efecto un caso extraordinario de supervivencia (de hecho, es el más antiguo del mundo) ${ }^{6}$. Ahora bien, es claro que la existencia de bipartidismos estables y protegidos por fuertes diseños institucionales no clausura necesariamente las dinámicas de representación democrática, como lo ilustra el caso de Estados Unidos y, sobre todo, de Inglaterra. Pero el colombiano podría ser mucho más restrictivo al menos desde tres puntos de vista: primero, la aglomeración de los partidos alrededor del centro es tal que desaparece la posibilidad de elegir entre alternativas políticas diferentes («olivos y aceitunos todos son unos», según el aforismo que proviene de fines del siglo XIX); segundo, las fuerzas tradicionales recurren sistemáticamente a métodos extrainstitucionales (una combinación de corrupción y violencia) para mantenerse en el poder; tercero, expresan mal o ignoran los intereses de los sectores populares. Creo que el primer aspecto está más o menos demostrado por la literatura (ver por ejemplo Gutiérrez, 1998a, 1998b), pero falta precisar en qué sentido la aglomeración colombiana se diferencia de las tendencias mundiales. Sobre el segundo también hay múltiples evidencias; apenas daré un par de ejemplos, aunque señalando que la situación no permite sacar inferencias tan directas como podría suponerse. Hay varios buenos estudios sobre el tercero (por ejemplo, Reyes, 1978), y lo tomaré por dado, aunque con algunas reservas ${ }^{7}$. Como fuere, en presencia de tales restricciones es crucial saber si el sistema político se ha alejado del bipartidismo tradicional, en qué medida y de qué forma.

2. Cierre como trampa institucionalizada. Las décadas de los 80 y 90 estuvieron caracterizadas por una vertiginosa actividad reformista: «apertura política» bajo Belisario Betancur (1982-1986), elección popular de alcaldes bajo Virgilio Barco

5. No digo que sea imposible mostrar que haya en realidad una diferencia cualitativa, sólo que por el momento no contamos con ninguna evidencia de que exista.

6. Antes de la guerra civil, la política estadounidense estaba protagonizada por los whigs y los demócratas jacksonianos (bastante diferentes de los demócratas contemporáneos). Así que nuestro bipartidismo es aproximadamente diez años más viejo que el de Estados Unidos. Naturalmente, los desenlaces diferenciales de los dos países hacen aún más difícil de explicar la estabilidad de nuestro sistema de partidos.

7. Los políticos tradicionales han bloqueado muchas reformas (comenzando por la agraria) y han aceptado otras pero con la esperanza de poder adaptarse después a las reglas de juego. No obstante, cada vez más -y sobre todo después de la Constitución de 1991- la resistencia a diversas operaciones modernizantes a gran escala y en ocasiones incluso la defensa de la economía ilegal expresaban intereses genuinos de sectores populares cuantitativamente significativos. No fueron pocas las ocasiones en que los políticos clientelistas se pusieron de parte de reinvindicaciones y movimientos sociales importantes, así que el panorama ahora es bastante menos claro que a finales de la década de 1970 . 
(1986-1990), nueva Constitución en el período de César Gaviria (1990-1994), diversos intentos de introducir mejoras en la Ley electoral, el sistema de partidos y el funcionamiento del Congreso bajo los Gobiernos Samper y Pastrana. Para algunos comentaristas la mayor parte de estos cambios ha sido cosmética o contraproducente, y sigue existiendo un sesgo en el régimen jurídico vigente que favorece a los partidos tradicionales. Pero es igualmente posible que las expresiones subnacionales de las fuerzas alternativas sean mucho más vigorosas que lo que es visible en las elecciones presidenciales o parlamentarias.

3. Cierre como clase política premoderna us. sociedad en proceso de modernización. Colombia sufrió en las últimas dos décadas transformaciones importantes: la urbanización del país, el elevamiento bastante radical de sus índices de escolaridad, el ingreso de nuevos actores políticos, la creación de identidades y sociabilidades, el papel creciente de los medios, el fortalecimiento de la presencia pública de la clase media, los técnicos y profesionales, etc. En cambio, los políticos tradicionales siguieron enquistados en sus prácticas y lenguajes tradicionales. Se puede demostrar empíricamente (Archer, citado en Nielson y Shugart, 1999; Gutiérrez, 1996) que en efecto los departamentos menos educados y poblados del país están groseramente sobrerrepresentados en el Congreso, lo que ha favorecido en términos generales al Partido Liberal ${ }^{8}$. Nielson y Shugart (1999) han defendido la hipótesis de que la sociedad urbana y moderna ha roto así sea parcialmente con los sectores más atrasados del bipartidismo, ayudando a fraguar nuevas mayorías?. Específicamente, la fractura rural-urbana sería la clave para la comprensión de la crisis del bipartidismo y de los efectos a largo plazo de la Constitución de 1991. Desde el punto de vista metodológico, esto se puede pensar como una hipótesis de muchas categorías (a cada nivel de desarrollo, un nivel de bipartidismo) o de sólo dos categorías (ciudades grandes con clases medias fuertes y exposición continua a los medios de comunicación vs. municipios atrasados).

4. Cierre como déficit de representación. Sectores sociales enteros son invisibles en la vida política colombiana. Obviamente, esto es una «endogenización» del tema de la propiedad y la desigualdad. ¿Cuántos obreros y campesinos hay en el

8. Esta sobrerrepresentación se obtuvo a través de dos vías completamente distintas: el cabildeo de las propias regiones que, gracias a las redes clientelistas, podían contar con buenas posibilidades de éxito; y el esfuerzo de intelectuales de avanzada, que intentaban romper el [efectivamente asfixiante] monopolio centralista de la capital.

9. El planteamiento de Nielson y Shugart tiene varios problemas técnicos, sobre los que no me quiero detener aquí. Vale la pena mencionar, sin embargo, la idea de que el voto urbano ayuda a crear una «mediana en todas las direcciones» en el espacio de preferencias de los electores. En la medida en que los autores sólo se refieren a una fractura (cleavage), la rural-urbana, la expresión no es muy esclarecedora. Además, tendrían que probar que esa fractura en efecto discrimina bien el comportamiento político, cosa que no parece exacta a la luz de la evidencia que presentamos aquí. Entre la abundante literatura introductoria al tema de centros políticos estabilizadores y medianas en todas las direcciones, destacaría Hinich y Munger (1979). 


\section{FRANCISCO GUTIÉRREZ SANÍN ¿SE HA ABIERTO EL SISTEMA POLÍTICO COLOMBIANO? UNA EVALUACIÓN DE LOS PROCESOS DE CAMBIO (1970-1998)}

Congreso? ¿Cuántos industriales y terratenientes? Al tenor de lo expuesto en el punto 3 , se podría también argumentar que la clase media, los profesionales y las nuevas sensibilidades tienen expresión magra -salvo excepciones espectaculares que confirman la regla- en el sistema político.

En síntesis, es preciso saber cómo ha evolucionado la preponderancia de los políticos tradicionales tanto en los cargos ejecutivos de elección popular como en los cuerpos colegiados a nivel nacional, departamental y municipal. Como se sugirió en 1, el caso colombiano tiene la ventaja (para el analista) de que una identificación entre clientelismo, clase política tradicional y partidos históricos, aunque sólo aproximativa, no parece forzar mucho las cosas; en otros países la situación es mucho más complicada. Aquella evolución debe contrastarse con procesos sociales y dinámicas de representación. El objetivo es comprender qué líneas de relación se pueden establecer entre tales dinámicas (modernización sin voz, déficit de representación) y desenlaces políticos. Es sobre esas líneas que se puede producir una comprensión de la noción de cierre que permita comparar eventualmente con otros casos.

\section{RESULTADOS}

\section{Breve advertencia metodológica}

El lector a quien las precisiones metodológicas le produzcan dolor de cabeza, puede perfectamente saltarse este acápite y volver a él sólo cuando sienta que la discusión de los indicadores lo haga necesario.

En adelante, calificaré a los partidos liberal y conservador de tradicionales, y a aquellos que no lo sean, de «terceras fuerzas», «tercerías» o «alternativas». Los tradicionales cogobernaron el país y tuvieron un claro predominio electoral en el período observado, pero en la actualidad existe la impresión de que estamos a las puertas de un cambio ${ }^{10}$. En 1970, estaba en plena vigencia el Frente Nacional, un acuerdo consocional (Hartlyn, 1993) que institucionalizó una severa limitación del acceso de las tercerías al poder (los parlamentarios de la ANAPO, la principal tercería en el Parlamento, para tomar posesión de su curul tenían que definir si eran anapistas liberales o conservadores). El país asistió al desmonte gradual del Frente (en los 70 y 80 ), a la apertura a nuevas formas de democracia local (década de los 80) y finalmente a una nueva Constitución (1991). ¿Cómo comenzar a caracterizar la evolución del régimen en términos de cierre o apertura?

Para hacerlo, tomé cuatro unidades de análisis: nación, departamento, ciudades y municipios. En el primer nivel, contemplé básicamente el Congreso, ya que las elecciones

10. Más o menos cada semana se anuncia la desaparición y muerte definitiva de los tradicionales. Es fácil burlarse de la incapacidad predictiva de los agoreros, pero vale la pena recordar que si finalmente sí se produce la catástrofe liberal conservadora, podrán cobrar un premio gordo con el proverbial «yo te lo dije». 
presidenciales han sido estudiadas suficientemente. Para efectos de este texto, baste decir que en 1970 el candidato presidencial del Frente Nacional ganó por una cifra muy exigua, en medio de verosímiles acusaciones de fraude por parte de los perdedores, la coalición populista ANAPO. En el resto del período, las terceras fuerzas tuvieron una presencia completamente marginal, con excepción de 1998 cuando Noemí Sanín obtuvo la tercera votación $"$ ". No está claro, sin embargo, que sea lícito calificar a Sanín de «no bipartidista», dado que su procedencia y buena parte de su votación son netamente conservadoras. En todo caso, según Pinzón (1998), en las ciudades hubo más votos para los candidatos de las tercerías (Sanín y el extremista de derecha Harold Bedoya) que en el resto del país. Esto podría corresponder a una tendencia que abarca todo el período, ya que no sólo la ANAPO sino las disidencias más audaces de los partidos tradicionales encontraron en el mundo urbano su nicho natural.

En cuanto al nivel departamental, sólo tuve en cuenta las asambleas. En la década de 1970 y 1980 ocuparon un papel muy importante en el sistema político, para después ir opacándose. Sin embargo, siguen conservando alguna vitalidad; varias propuestas para acabarlas han sido derrotadas en el Congreso. Más aún, los niveles de participación en las elecciones para asambleas han aumentado consistentemente. En Colombia también se eligen popularmente los gobernadores, pero apenas desde 1992.

En cambio para los centros urbanos se tuvieron en cuenta tanto las elecciones legislativas (Concejo) como las ejecutivas (alcalde). De las primeras se tiene una serie larga, que comienza en 1972 (con un bache en 1990), y de las segundas una corta (comenzaron en 1988). La distinción entre centros urbanos se llevó a cabo utilizando uno de dos criterios. Primero, siguiendo al DANE, se clasificaron como ciudades Bogotá, Cali, Medellín, Barranquilla, Cúcuta, Bucaramanga, Pereira, Pasto, Ibagué, Manizales, Cartagena y Montería. A estos 12 municipios se sumaron otros 208, una muestra aleatoria (buscando el tamaño óptimo de la muestra con el método expuesto en Ramírez, 1984) del total del país ${ }^{12}$. Segundo, con base en el trabajo de Sarmiento et al. $(1998)^{13}$, se dio a cada municipio, incluyendo las ciudades, una calificación entre 1 y 6 de acuerdo con su grado de desarrollo. En general, el discriminante binario (ciudades vs. municipios) ofreció, como era de esperarse, resultados un poco mejores que el más elaborado de seis niveles de Sarmiento. Sin embargo, en este texto apenas se ofrecen resultados iniciales, y es posible que en el futuro se encuentre que la escala de Sarmiento discrimina bien más fenómenos políticos de los que se incluyen aquí. Supuse que tanto esa escala como la dicotomía rural urbano son fijas para todo el período, lo que es un tanto, pero no

11. Además, Noemí era la segunda preferencia de los dos primeros candidatos, así que es razonable afirmar que hubiera ganado casi con cualquier modalidad de voto posicional.

12. Por supuesto, en esta muestra no se incluyeron las «ciudades». Era físicamente imposible trabajar con el total de más de mil municipios, entre otras razones por simple precariedad de las fuentes de información.

13. Sin duda una las investigaciones más serias que se han realizado en el país sobre el ámbito municipal. La categorización de SARMIENTO (1998) fue construida usando una sofisticada técnica de escalamiento multidimensional, incorporando criterios demográficos, económicos y sociales. 
terriblemente, inexacto ${ }^{14}$. En adelante, llamaré «ciudades» a los 12 centros urbanos más desarrollados, y municipios a los demás.

Para la construcción de indicadores, enfrenté varias dificultades cuya solución no es completamente clara. La principal es que la desinstitucionalización de los partidos hace muy difícil saber quién pertenece a qué. Me guié en este terreno por el siguiente criterio: en el nivel nacional, hacer un análisis caso por caso de las situaciones dudosas; en el nivel subnacional, atenerme a la forma de presentación de la registraduría nacional. La mayoría de las situaciones dudosas están relacionadas con ex miembros de los partidos tradicionales, que los abandonan, forman movimientos efímeros para reforzar su posición o semiclandestinizan su militancia para no chocar a la opinión pública ${ }^{15}$. Intenté ser consistente en el siguiente sentido: entre mayor tiempo «completamente» fuera del partido, más fuerte su ruptura pública y mayor diferencia a nivel de discurso, más probabilidad de tomar al candidato como «alternativo» y no como tradicional ${ }^{16}$.

En lo que sigue, se usan tres clases de indicadores. Los primeros sirven para caracterizar dinámicas comunes a todos los sistemas políticos:

\section{Indicador 1}

Partido efectivo: En todos los cuerpos colegiados, se usó el número de curules para hallar el partido efectivo ${ }^{17}$. En las elecciones para alcalde, en cambio, se computaron votos. Así que se trata en realidad de dos cosas distintas, aunque muy relacionadas ${ }^{18}$.

Desviación de la proporcionalidad: Sólo se contabilizó a nivel nacional.

Participación electoral.

Los segundos sirven para caracterizar dinámicas específicas del sistema político colombiano. En particular, había tres problemas importantes a resolver. A. hasta qué punto ha aumentado la diversidad dentro del sistema; B. qué poder real tiene esa

14. Los niveles relativos de desarrollo cambian muy despacio en relación con los fenómenos políticos. Además, una corrección de hecho reforzaría las conclusiones del artículo, puesto que sólo podría mejorar los niveles de «modernidad» al principio del período.

15. Véase cómo se concibió la campaña liberal de Samper, un caracterizado hombre de partido: «La principal debilidad de Samper era su imagen de cercanía con la clase política liberal y su asociación con el "viejo país"...se diseñó un esquema de campaña moderno y novedoso, que se debía desarrollar con independencia a la maquinaria liberal y centrado en las preocupaciones éticas». (Dirección Regional de fiscalías. Transcripción de la ampliación de indagatoria rendida por el señor Fernando Botero Zea en la instrucción penal n. ${ }^{\circ} 25368$ el día 22 de enero de 1996).

16. Obviamente, no se tienen a la mano soluciones perfectas aparte de rezar por una razonable reinstitucionalización de la actividad política. Afinando criterios, con el tiempo se podría llegar a mecanizar la clasificación incluso en este mundo radicalmente desinstitucionalizado, a través de un ejercicio de «reconocimiento de patrones», método con el que ya he obtenido algunos resultados iniciales. Una vez más, alguna mejora en este sentido tendría el efecto de reforzar las conclusiones presentadas aquí, puesto que seguramente haya una [leve] subestimación de las fuerzas tradicionales, que desde hace más de 10 años conscientemente intentan mimetizarse como «renovadoras» y «cívicas».

17. En general, no hay datos de votos por partido para los concejos municipales.

18. Pero no sumé peras con manzanas. Al concluir más adelante que partido efectivo discrimina ciudades de municipios en elecciones ejecutivas, pero que en cambio no lo hace en las elecciones legislativas, no mezclé el criterio de curules con el de votos. 
diversidad (o su complemento, los tradicionales); C. qué tanta estabilidad tiene el dominio de un partido a nivel local o departamental (respondiendo a una pregunta ya planteada hace tiempo en Pinzón, 1989). Enfrenté todos ellos usando uno de los varios indicadores de poder relativo de voto dentro de un cuerpo colegiado, el índice de Banzhaf ${ }^{19}$. Como la unidad de análisis al producir el índice es el partido político, queda por fuera el faccionalismo intrapartidario, uno de los aspectos más relevantes de la política colombiana a través de su historia ${ }^{20}$. Pero, ¿votan los partidos colombianos unidos? La respuesta no es clara. A nivel congresional, lo han hecho durante casi todo el período, a veces enfrentándose con el Ejecutivo pero manteniendo pese a todo un grado apreciable de cohesión interna ${ }^{21}$. En los niveles subnacionales, parece ser que predomina el faccionalismo interno cuando el partido dominante carece de oposición significativa pero, a medida que ésta aparece, disminuye la dispersión ${ }^{22}$. Esto tiene un gran valor descriptivo, pero no afecta demasiado el sentido del índice, puesto que éste mide la capacidad de formar alianzas, esto es, de atraer aliados. Dicho de otra manera, caracterizar el poder de voto de una organización con Banzhaf no significa partir del supuesto de que siempre vota unida; más bien, dice que si votara unida tendría x o y poder para formar coaliciones. Expresa un potencial de poder, y en ese sentido lo hace muy bien $^{23}$. En el caso colombiano, habría que realizar posteriormente el ejercicio de evaluar series de tiempo del poder de voto de los dos partidos unidos, porque hay buenas evidencias de que eran capaces de unirse en presencia de algún peligro «externo», por lo menos hasta hace muy poco.

Una vez con las series de tiempo del índice de Banzhaf para cuerpos colegiados, se procedió a construir valores agregados que permitieran caracterizar a la serie (aquí la dificultad radica en que el índice no se puede sumar o restar (no es aditivo):

\section{Indicador 2}

Rotación: Número de veces sobre el total de elecciones que ha cambiado el partido con mayor poder de voto dentro del cuerpo colegiado. Nótese que estos eventos sí

19. Por supuesto, era ingenuo medir poder relativo simplemente como la proporción de escaños del grupo A en relación con el total. Puedo tener 49 por ciento de los votos en una sociedad anónima, y carecer completamente de poder. Los indicadores más usados para evaluar poder en los cuerpos colegiados son los de Banzhaf y de Shapley, que miden dos dimensiones de poder complementarias.

20. Pero no se puede pretender «descubrirlo todo» con un solo modelo, así que el tema se deja para futuros análisis.

21. La bancada liberal oficialista, por ejemplo, actuó de manera bastante cohesionada bajo los Gobiernos de Belisario Betancur (cuando estuvo en la oposición), Virgilio Barco y César Gaviria. En los dos últimos se enfrentó varias veces al Ejecutivo, de su propia bandería, pero manteniendo siempre algún grado de disciplina interna. Incluso bajo Pastrana su faccionalismo ha sido moderado (dos grupos). Solamente después de la Constitución se produjeron votaciones nominales, y allí casi siempre los liberales van unidos (con algunas defecciones cruzadas entre ellos y sus adversarios). Me baso para esta relación en las Gacetas del Congreso.

22. Como se desprende de la lectura de varios tomos de actas de asambleas departamentales y concejos municipales en la década de 1980.

23. Una buena explicación del índice de Banzhaf se encuentra en TAYLOR (1995). Una exposición mucho más complicada, pero más completa, es la de FELSENTHAL y MACHOVER (1998). 
son aditivos, se pueden sumar y restar y producen un índice entre 0 y 1 que caracteriza toda la serie.

Partido dominante: Número de veces sobre el total de municipios (respectivamente, ciudades o departamentos) en que un partido ha ganado todas las elecciones.

Dominio tradicional: Número de veces sobre el total de municipios (respectivamente, ciudades o departamentos) en que uno de los dos tradicionales tuvo mayor poder de voto.

Dictadura: Número de veces sobre el total de municipios (respectivamente, ciudades o departamentos) en que coinciden existencia de un partido dominante y 0 rotación.

Quintil 3: Número de veces en que el partido liberal ha obtenido un valor de Banzhaf inferior a 0,75 .

Por último, utilicé algunos indicadores para argumentaciones específicas. Ellos son, por decirlo así, «transparentes» (homicidios políticos por año, por ejemplo); no requieren de explicación adicional. Salvo indicación en contrario, la fuente de datos es la registraduría nacional. Todos los cálculos son míos ${ }^{24}$.

Si el lector ha sobrevivido a estas especificaciones, áridas pero necesarias, se encontrará en el próximo acápite con algunas sorpresas interesantes.

\section{Bipartidismo pegajoso}

Los partidos tradicionales colombianos están seriamente desinstitucionalizados y su desprestigio ante sectores importantes de la opinión los ha llevado, como ya se observó, a desarrollar campañas en las que la afiliación política se clandestiniza. Con todo y ello, el sistema político colombiano apenas si se ha alejado del bipartidismo. No deja de ser sorprendente la tremenda estabilidad de los resultados electorales en un país en proceso de cambio violento y acelerado, y desarrollando simultáneamente reformas institucionales profundas. Como se observa en la Tabla I A, en realidad el guarismo de partido efectivo en el Congreso disminuyó en el período 70-90, y solamente después, bajo el impacto de las reformas constitucionales, repuntó y alcanzó los niveles que tenía en 1970. Algo similar se puede decir del poder de voto efectivo no sólo de las alternativas al bipartidismo (que en 1970 era una poderosa pero efímera organización populista, la ANAPO, mientras que en 1998 son jirones dispersos y pequeños) sino también de los conservadores, que al final estaban en peligro de encontrarse frente a una eventual

24. Desarrollé sendos programas en computador (en Mathematica 4.0) para calcular el índice de Banzhaf y los indicadores derivados de él. Anteriormente había elaborado un programa para sacar el valor de Shapley, el otro indicador de poder de voto, y lo apliqué al Congreso colombiano en 1998b. Pero en este caso al «traducir» de Shapley a Banzhaf no cambian mucho las cosas, así que al analizar el Congreso colombiano me contento con una descripción verbal de la evolución del poder de voto, remitiendo al lector al texto referido.

Las correlaciones estadísticas fueron calculadas usando Mathematica (prueba de la diferencia de medias) $\mathrm{y}$, a veces, SPSS 9.0. 
dictadura liberal no sólo en las votaciones por mayoría simple sino también en las calificadas ${ }^{25}$ (Gutiérrez, 1998b). A nivel departamental, en 1970 el indicador de partido efectivo oscilaba entre 2 y 3 en la mayoría de las asambleas, para después caer bruscamente en la década de los 80 . En los 90 hubo un repunte, sin recuperar la diversidad inicial (Tabla I B).

Tabla I A: Evolución de partido efectivo Senado y Cámara

\begin{tabular}{c|c|c}
\hline \multicolumn{3}{|c}{ Partido efectivo para elecciones al Congreso 1970-1998 } \\
\hline Año & Senado & Cámara \\
\hline 1970 & 2,94 & 2,98 \\
\hline 1974 & 2,17 & 2,28 \\
\hline 1978 & 2,01 & 2,06 \\
\hline 1982 & 1,97 & 1,98 \\
\hline 1986 & 2,46 & 2,45 \\
\hline 1990 & 2,22 & 2,18 \\
\hline 1991 & 2,91 & 3,01 \\
\hline 1994 & 2,82 & 2,71 \\
\hline 1998 & 3,77 & 3,17 \\
\hline
\end{tabular}

Tabla I B: Evolución de partido efectivo asamblea

\begin{tabular}{c|c|c|c}
\hline Año/Partido efectivo & $\begin{array}{c}\text { Proporción de asambleas con número de } \\
\text { partido efectivo entre 1 y 2 }\end{array}$ & Entre 2 y 3 & $>3$ \\
\hline 1972 & 0,25 & 0,68 & 0,06 \\
\hline 1974 & 0,41 & 0,59 & 0 \\
\hline 1976 & 0,44 & 0,56 & 0 \\
\hline 1978 & 0,74 & 0,26 & 0 \\
\hline 1980 & 0,68 & 0,32 & 0 \\
\hline 1982 & 0,89 & 0,11 & 0 \\
\hline 1984 & 0,63 & 0,37 & 0 \\
\hline 1986 & 0,74 & 0,26 & 0 \\
\hline 1988 & 0,47 & 0,42 & 0,11 \\
\hline 1990 & 0,74 & 0,26 & 0 \\
\hline 1992 & 0,37 & 0,63 & 0 \\
\hline 1994 & 0,53 & 0,47 & 0 \\
\hline 1997 & 0,47 & 0,53 & 0 \\
\hline
\end{tabular}

Un escrutinio especial merecen los concejos municipales, por dos razones. En primer lugar, las reformas más profundas del sistema político y el proceso de descentralización tenían en mente a los municipios. En segundo lugar, los grupos armados han ido diseñando una estrategia que contempla a los municipios como principal objetivo. ¿Qué

25. En caso de que los liberales votaran unidos, por supuesto. 
FRANCISCO GUTIÉRREZ SANÍN

¿SE HA ABIERTO EL SISTEMA POLÍTICO COLOMBIANO? UNA EVALUACIÓN

DE LOS PROCESOS DE CAMBIO (1970-1998)

Tabla I C: Evolución partido efectivo concejos de ciudades $\mathrm{N}=208$

\begin{tabular}{c|c|c|c}
\hline Año/Partido efectivo & $\begin{array}{c}\text { Proporción de asambleas con número de } \\
\text { partido efectivo entre 1 y 2 }\end{array}$ & Entre 2 y 3 & $>3$ \\
\hline 1972 & 0,08 & 0,92 & 0 \\
\hline 1974 & 0,08 & 0,92 & 0 \\
\hline 1976 & 0,25 & 0,75 & 0 \\
\hline 1978 & 0,33 & 0,58 & 0,08 \\
\hline 1980 & 0,66 & 0,17 & 0,17 \\
\hline 1982 & 0,67 & 0,33 & 0 \\
\hline 1984 & 0,58 & 0,42 & 0 \\
\hline 1986 & 0,25 & 0,58 & 0,17 \\
\hline 1988 & 0,33 & 0,58 & 0,08 \\
\hline 1990 & 0,67 & 0,33 & 0 \\
\hline 1992 & 0,17 & 0,42 & 0,42 \\
\hline 1994 & 0,33 & 0,66 & 0 \\
\hline 1997 & 0,33 & 0,58 & 0,1 \\
\hline
\end{tabular}

Tabla I D: Evolución partido efectivo concejos de municipios $\mathrm{N}=208^{26}$

\begin{tabular}{c|c|c|c}
\hline Año/Partido efectivo & $\begin{array}{c}\text { Proporción de asambleas con número de } \\
\text { partido efectivo entre 1 y 2 }\end{array}$ & Entre 2 y 3 & $>3$ \\
\hline 1972 & 0,49 & 0,47 & 0,04 \\
\hline 1974 & 0,75 & 0,25 & 0 \\
\hline 1976 & 0,846 & 0,149 & 0 \\
\hline 1978 & 0,92 & 0,08 & 0 \\
\hline 1980 & 0,96 & 0,03 & 0 \\
\hline 1982 & 0,96 & 0,04 & 0 \\
\hline 1984 & 0,947 & 0,0048 & 0 \\
\hline 1986 & 0,87 & 0,125 & 0 \\
\hline 1988 & 0,75 & 0,21 & 0,04 \\
\hline 1992 & 0,41 & 0,3 & 0,29 \\
\hline 1994 & 0,68 & 0,25 & 0,06 \\
\hline 1997 & 0,66 & 0,24 & 0,1 \\
\hline
\end{tabular}

está sucediendo en este nivel? En 1972, el país se dividía más o menos por partes iguales entre concejos unipartidistas y bipartidistas. Pero a renglón seguido se produjo un cierre, consistente en que en casi todos los concejos predominaba ampliamente un solo partido. Hacia finales de los 80 comenzó un proceso en dirección contraria -lo cual también produce cierto asombro, porque precisamente entonces entraban los grupos armados a pelear por el poder local-, pero en la actualidad no se han alcanzado los niveles de apertura, medidos a través del partido efectivo, que existían en 1970 (Tabla I D).

26. No hay datos para 1990. 
Sin embargo, hay otras formas de ver si el sistema político efectivamente se ha abierto o no. Por ejemplo, es claro que actualmente hay muchas «más voces» dentro del sistema que antes: la cantidad de grupos con representación en el Congreso es mayor, incluso después de ajustar por el factor de desinstitucionalización de las fuerzas tradicionales. Algo similar ha sucedido en los concejos.

Gráfico I: Cantidad de grupos representados en los concejos y ciudades (promedio)

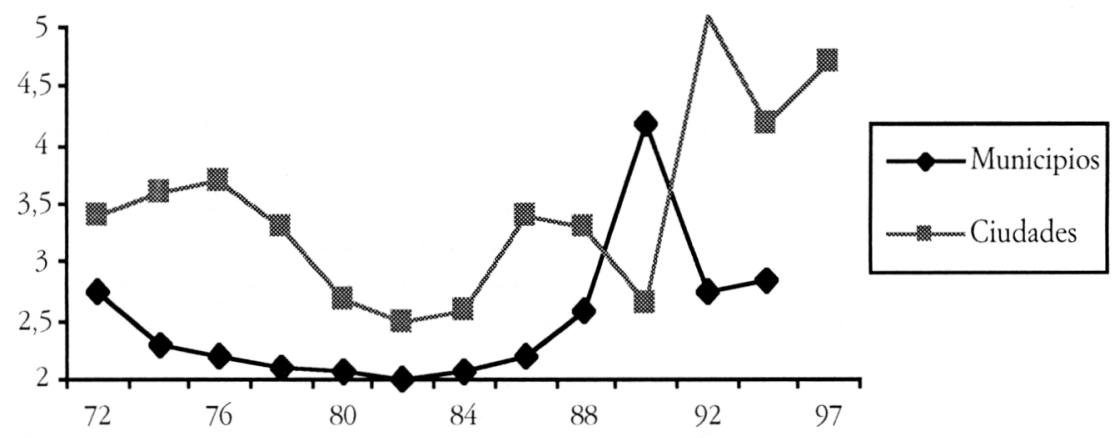

Fuente: Elaboracion propia.

Se observa aquí también el bache de los 80 . Las ciudades aparentemente expresan mayor diversidad pero si se descontara por el tamaño de los concejos ${ }^{27}$, la diferencia, de permanecer, sería mínima. Se oyen, pues, nuevas voces; pero no tienen una gran oportunidad de hacerse valer. Como se observa en el Gráfico II, con la sola excepción de 1972 y 1992, una u otra de las fuerzas tradicionales fue absolutamente dominante ${ }^{28}$ en términos de poder de voto en el 80 por ciento de los concejos municipales (barras negras en el gráfico). En la medida en que es práctica común realizar coaliciones bipartidistas en la mayor parte de esas corporaciones, incluso esta cifra podría subestimar seriamente el poder local de los tradicionales.

Pero además incluso dentro del mundo de lo tradicional hay otras dimensiones de cierre. Si por «rotación» definimos el número de veces en que cambia el partido dominante según su poder de voto de una elección a otra, es posible medir el conjunto de rotaciones sobre el total de municipios, y tener así un indicador de la estabilidad del sistema que va entre 0 y 1 . Básicamente, lo que se evalúa es la resistencia al cambio. El sistema colombiano (tanto a nivel de Congreso como de Asamblea y municipio) ha permanecido todos estos años bastante cerca de 0 , con un cierto movimiento hacia arriba a principios de la década de los 90 que parece haberse enfriado rápidamente (ver Gráfico III ${ }^{29}$.

27. En un municipio pequeño el Concejo puede tener 7 miembros; en Bogotá tiene 40 .

28. Es decir, podían ganar cualquier elección simple sin contar con aliados. En los concejos no hay votaciones calificadas.

29. Las asambleas y el Congreso tienen una proporción aún menor de rotaciones. 
DE LOS PROCESOS DE CAMBIO (1970-1998)

Gráfico II: Proporción de municipios en los que una de las fuerzas tradicionales (o los liberales o los conservadores separadamente)

es absolutamente dominante en términos de poder de voto. Por año de elección

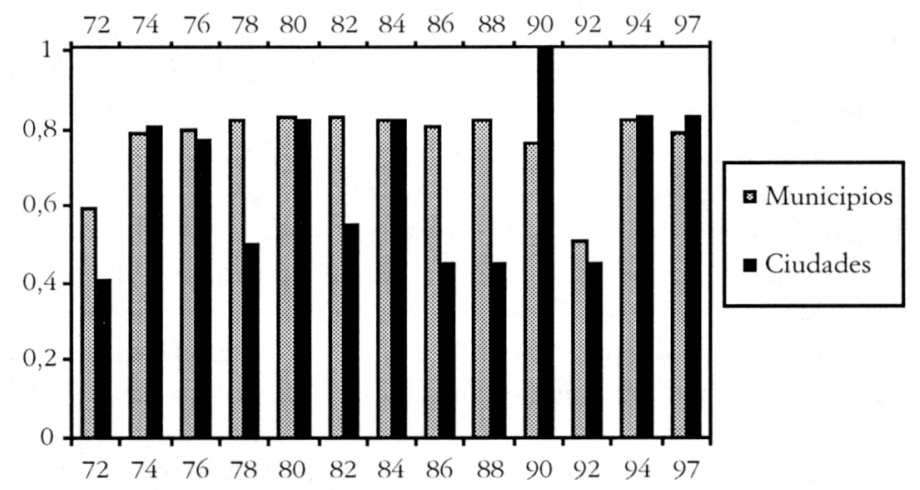

Gráfica III: Proporción de rotaciones en concejos municipales

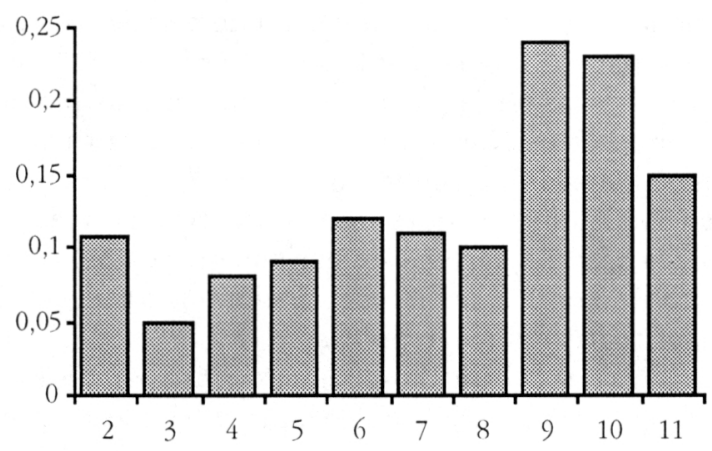

De los 210 municipios considerados, 49 (más del 20 por ciento) vivieron todos estos años «dictaduras locales»: estuvieron sometidos al dominio de un solo partido, que contaba con un poder de voto absoluto. Es verdad que las elecciones populares de alcaldes muestran un panorama mucho más alentador, especialmente en las ciudades grandes. Pero hay factores que permanecen constantes. En las cuatro elecciones de este tipo realizadas hasta ahora, el partido liberal obtuvo aproximadamente entre 35 y 55 por ciento de las alcaldías del país. Las otras fuerzas ganaron una considerable participación, pero básicamente a costa de los conservadores (Querubín, Sánchez y Kure, 1998). Encontramos una clara analogía con lo sucedido en el Congreso: evolución desde bipartidismo a un sistema de «partido y medio», con los liberales como fuerza dominante, los conservadores perdiendo terreno y una nube heterogénea de nuevas fuerzas intentando abrirse paso. 
La evolución de las reglas de juego y el uso de métodos extra-institucionales

Es muy difícil encontrar evidencia empírica a favor de la tesis de que las reglas de juego han estado diseñadas para favorecer al bipartidismo. En realidad, una de las constantes de los cambios institucionales que han tenido lugar desde 1970 hasta hoy es el intento consciente y explícito de desmontar así fuera parcialmente el bipartidismo. De lo único que se puede acusar a los arquitectos de este proceso es de gradualismo. Aparte de múltiples reformas importantes pero puntuales (elección popular de alcaldes, por ejemplo) y de esfuerzos aperturistas, se produjeron en el período dos hitos trascendentales. Primero el desmonte del Frente Nacional, lo que implicaba una gran cantidad de ajustes. El último de ellos se dio en $1986^{30}$. En consecuencia, el acuerdo consociacional (Hartlyn, 1993) que excluía del ejercicio del poder a las terceras fuerzas dejó de existir. Segundo, la Constitución de 1991, que pretendía precisamente institucionalizar el ethos anticlientelista que la inspiró.

Es preciso hacer hincapié en que la batería anticlientelista incorporada a la Constitución no es inofensiva. El conjunto de diseños institucionales pergeñado por los constituyentes para quebrar las resistencias clientelistas es impresionante: circunscripción nacional para Senado; tarjetón; no acumulación de mandatos; modificación del calendario electoral; desaparición de las suplencias; pérdida de la investidura y reemplazo de la inmunidad parlamentaria por fuero; aumento drástico del régimen de las incompatibilidades, entre otros. Varios de estos cambios institucionales tuvieron efectos profundos e inmediatos. Por ejemplo, sin el paso de la inmunidad al fuero no habría habido «Proceso 8000», uno de los eventos anticorrupción más grandes de América Latina que llevó a la cárcel a decenas de parlamentarios del partido mayoritario. El nuevo calendario electoral, o la circunscripción nacional, implicaron así mismo un cambio real en las reglas del juego político.

Se argumenta con frecuencia que la llamada «operación avispa» (consistente en que cada partido presenta múltiples listas por cada cargo a proveer), ideada por el ex presidente López Michelsen casi en simultánea con la nueva Constitución, fue en los 90 la pieza maestra del cierre institucional. Pero esto no es tan claro. De hecho, la «operación avispa» fue concebida en parte también como una maquinación anticlientelista, que le quebraría el espinazo a los barones electorales. La otra cara de la moneda es, por supuesto, la utilización que hicieron de la operación los pequeños y medianos caciques de los partidos tradicionales, uno de cuyos efectos indirectos fue una dramática desinstitucionalización. Pero aunque el sistema electoral colombiano sí se deja manipular por las fuerzas dominantes, indeseable característica que comparte con muchísimos otros, su comportamiento en términos de desviación de la proporcionalidad es bueno no sólo en el contexto latinoamericano sino, creo, mundial (ver Tabla II). Esto quiere decir que la proporción de miembros del partido A en la población se parece mucho a la proporción

30. Por lo que Martz argumenta que el desmonte no se produjo sino en 1986; una inexactitud, puesto que si bien no terminó completamente sino en esa fecha, había comenzado mucho antes. 
FRANCISCO GUTIÉRREZ SANÍN

¿SE HA ABIERTO EL SISTEMA POLÍTICO COLOMBIANO? UNA EVALUACIÓN

DE LOS PROCESOS DE CAMBIO (1970-1998)

Tabla II: Desviación de la desproporcionalidad comparada

Congresos Colombia, Chile y Venezuela

\begin{tabular}{|c|c|c|}
\hline \multicolumn{3}{|c|}{ Desproporcionalidad para elecciones colombianas a Congreso. 1970-1998 } \\
\hline 1974 & 0,042 & 0,022 \\
\hline 1978 & 0,042 & 0,028 \\
\hline 1982 & 0,026 & 0,023 \\
\hline 1986 & 0,037 & 0,045 \\
\hline 1990 & 0,035 & 0,018 \\
\hline 1991 & 0,069 & 0,064 \\
\hline 1994 & 0,065 & 0,112 \\
\hline 1998 & 0,122 & 0,121 \\
\hline Año & Senado & Cámara \\
\hline \multicolumn{3}{|c|}{ Desproporcionalidad para elecciones a Congreso en Chile. 1961-1997 } \\
\hline Año & Senado & Cámara de Diputados \\
\hline 1961 & 0,115 & 0,049 \\
\hline 1965 & 0,146 & 0,122 \\
\hline 1969 & 0,086 & 0,099 \\
\hline 1973 & 0,028 & 0,018 \\
\hline 1989 & 0,105 & 0,118 \\
\hline 1993 & 0,104 & 0,079 \\
\hline 1997 & 0,135 & 0,117 \\
\hline \multicolumn{3}{|c|}{ Desproporcionalidad sistema electoral venezolano } \\
\hline Año & Senado & Cámara \\
\hline 1963 & 0,16 & \\
\hline 1968 & 0,18 & \\
\hline 1973 & 0,15 & 0,11 \\
\hline 1978 & 0,16 & 0,07 \\
\hline 1983 & 0,17 & 0,08 \\
\hline 1988 & 0,19 & 0,08 \\
\hline 1993 & 0,14 & 0,09 \\
\hline
\end{tabular}

de miembros de ese partido en el Congreso: hay una aceptable traducción de preferencias políticas a curules.

¿Podría ser que las limitaciones institucionales existentes en los 70 fueron reemplazadas por un cierre extrainstitucional en los 80 y 90 , y que esto explica la estabilidad de nuestro bipartidismo? La respuesta podría plantearse tanto en términos de corrupción como de violencia. En ambos terrenos hay bastante por indagar. Daré sólo un ejemplo de los efectos que puede tener el cierre extrainstitucional. Colombia tiene una altísima tasa de homicidios políticos y, aunque no parece haber estudios cuantitativos al respecto, se puede conjeturar cómodamente que «tienen signo»: la probabilidad de que un dirigente, activista de izquierda o líder social sea asesinado, es más alta que la de que sea asesinado un activista o dirigente de los partidos tradicionales ${ }^{31}$. El

31. Nótese que tanto en el caso del homicidio como en el de la [narco]corrupción la comparación de partido a partido debe hacerse controlando por tamaño. La izquierda es apenas una ilustración, 
Gráfico IV es una ilustración bastante elocuente de lo que al parecer ha sucedido. Entre 1988 y 1995, algunos de los grupos surgidos de acuerdos de paz (quedan por fuera del conteo algunos significativos, como las milicias de Medellín) han puesto tantos o más muertos que los partidos liberal y conservador juntos, pese a constituir fuerzas electoralmente muy pequeñas. Por supuesto, el argumento debe ser refinado, por ejemplo con análisis de poblaciones (verbigracia alcaldes) y regiones específicas, pero en principio parece sostenerse. Continuando en el mundo de las conjeturas, una característica del período postfrentenacionalista sería el crecimiento en alguna proporción de la vulnerabilidad de los tradicionales ${ }^{32}$; pero sigue existiendo un brutal desbalance ${ }^{33}$. Saber esto es decisivo para interpretar la política colombiana, por al menos tres razones. Ante todo, la simple fuerza bruta es capaz de acabar con denominaciones políticas enteras, como de hecho ha sucedido en Colombia, y dispersar sus bases sociales. Éstas pueden adoptar después preferencias políticas completamente diferentes, incluso si la intimidación directa ha desaparecido ${ }^{34}$. Segundo, como lo ha mostrado una larga tradición de investigación empírica comparativa, los países con tasas más altas de violencia política son los «semirrepresivos». Es decir, la violencia política se comporta frente a la represión como una U invertida, siendo los regímenes muy cerrados o muy democráticos relativamente invulnerables ${ }^{35}$. Colombia es un buen ejemplo de país semirrepresivo (terror contra la oposición, tragedia humanitaria, pero a la vez elecciones más o menos competitivas y Estado de derecho que no se puede reducir a lo puramente cosmético), pero con la particularidad de que la represión se ejerce anárquica y descentralizadamente. Por tanto, la violencia se combina con incertidumbre generalizada (y consiguientemente alta aversión al riesgo por parte de muchos actores). Todo ello perjudica de manera directa o indirecta a las nuevas fuerzas.

pues evidentemente existen muchas fuerzas nuevas que no son de izquierda. Algunas de ellas también han resultado ser bastante vulnerables.

32. Pero sobre todo de aquellos tradicionales que adoptan posiciones críticas.

33. ¿Es necesario decirlo? Lo ideal sería que bajaran hasta 0 los homicidios políticos para activistas de cualquier denominación.

34. Sin contar el efecto de demostración que el partidicio tiene sobre candidatos y votantes ulteriores.

35. Muller, E. M. Income inequality, regime repressiveness, and political violence. American Sociological Review, 1985, vol. 50, 47-61; Muller, E. N. y SELIGSON, M. A. Inequality and insurgency. American Political Science Review, 1987, vol. 81, 425-451; WEEDE, E. Some new evidence on correlates of political violence: Income inequality, regime repressiveness, and economic development. European Sociological Review, 1987, vol. 3, 97-108; SСНОСK, Kurt. A conjunctural model of political conflict. The impact of political opportunities on the relationship between economic inequality and violent political conflict. Journal of Conflict Resolution, 1996, vol. 40, n." 1, 98-133. Esto, de paso, debería cerrar, o al menos redireccionar, un debate más o menos bizantino que se ha desarrollado en Colombia alrededor de la posible causalidad del cierre del sistema político sobre la violencia. Unos atribuyen a ese cierre males enormes, sin mayor fundamentación empírica, apoyándose en la intuición de que a mayor cierre mayor violencia. Otros niegan esa línea de causalidad, basándose en el hecho de que ha habido países mucho más cerrados, y bastante menos violentos, que Colombia. El comportamiento como una U invertida deja sin piso ambos argumentos. 
Gráfico IV: Asesinato de dirigentes políticos $1988-1995^{36}$

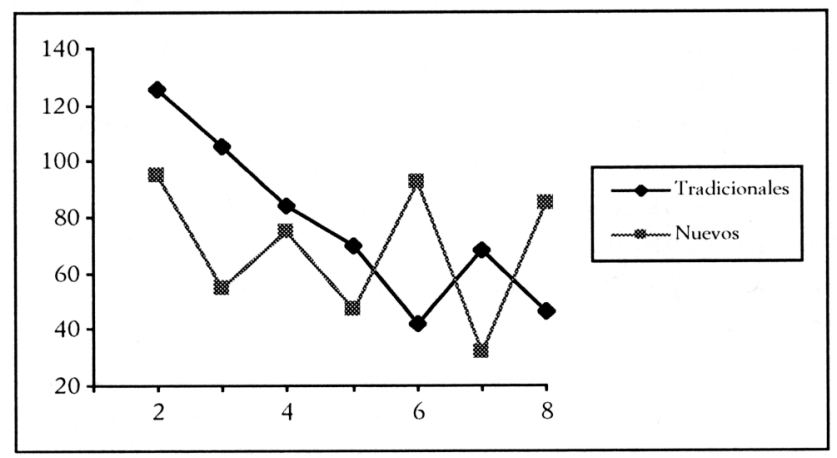

Tercero, en un ambiente de altos niveles de violencia, incertidumbre e impunidad, es de suponer que los grupos o líderes críticos tanto frente a los partidos tradicionales como frente a la sociedad formen adaptativamente sus preferencias ${ }^{37}$ : se volverán minimalistas para evitar convertirse en objetivo militar. De hecho, hay evidencias empíricas que apuntan precisamente en esa dirección (comenzando con la dramática declaración de Navarro al heredar la jefatura de la AD M-19, según la cual su máxima prioridad era evitar que lo mataran ${ }^{38}$. Si esto es así, el sistema político colombiano ha sido achatado artificialmente, y las formaciones nuevas se portan como si fueran bastante centristas, aunque no lo harían si el entorno fuera un poco menos violento y más predecible. Siguiendo esta línea de razonamiento, el achatamiento artificial de nuestro sistema político da una ventaja adicional -y enorme- a los partidos tradicionales, en la

- medida en que si todos los candidatos se asemejan mucho, el votante se inclina por la marca conocida.

Éstas son algunas de las maneras en que la represión distorsiona nuestro sistema político. Quiero sostener, empero, que descifrarlas no explica automáticamente a las mayorías tradicionales. En este terreno hay tanto vacíos como inconsistencias. En cuanto a los primeros, no hay un estudio serio que asocie indicadores de represión (por ejemplo, tasas de homicidio político por un multiplicador de «signo») con indicadores de bipartidismo (partido efectivo, valga por caso) a nivel departamental o municipal. Ignoramos si hay alguna clase de correlación entre unos y otros, y mientras no se sepa esto es difícil decir algo concluyente. De hecho, no parece obvio que haya siquiera una buena correlación a nivel nacional entre nivel de represión y votación por terceros. Más aún, hay

36. Fuente: Presidencia de la República-Consejería de Paz. Las agrupaciones que se cuentan como tradicionales son Partido Liberal y Partido Conservador. Las agrupaciones que se cuentan como nuevas son Unión Patriótica, Esperanza, Paz y Libertad y Alianza Democrática M-19.

37. ELSTER, Jon. Uvas amargas. Sobre la subversión de la racionalidad. Barcelona: Ediciones Península, 1988.

38. PeñaRAndA, Ricardo y Guerrero, Javier (comps.). De las armas a la política. Bogotá: Tercer Mundo Editores-Iepri (Un), 1999. 
claras anomalías de la «explicación represiva». En la mayoría de los territorios con alta influencia de la guerrilla los partidos tradicionales gozan de excelente salud, y se observa que tienen un margen de maniobra lo suficientemente amplio como para utilizar a los insurgentes a la hora de dirimir sus conflictos faccionales ${ }^{39}$. Hay además una notable insensibilidad del bipartidismo a la influencia directa de grupos armados de diferente tendencia ${ }^{40}$. La votación para alcalde en los cinco municipios de la zona de despeje sugiere que los tradicionales en realidad han mejorado allí su situación relativa en los últimos $a_{n ̃}{ }^{41}{ }^{4}$ (ver Tabla III). Por último, simplemente no parece verosímil atribuir preferencias que se expresan de manera tan constante durante décadas sólo a una combinación de miedo y corrupción.

Tabla III: Votos por tipo de organización para las elecciones de alcalde entre 1988 y 1997 en los municipios de Mesetas, La Uribe, Macarena, Vista Hermosa y San Vicente

\begin{tabular}{c|c|c|c}
\hline Año/Tipo de organización & Liberales & Conservadores & Otros \\
\hline 1988 & 0,25 & 0,25 & 0,50 \\
\hline 1990 & 0,50 & 0,00 & 0,50 \\
\hline 1992 & 0,20 & 0,20 & 0,60 \\
\hline 1994 & 0,80 & 0,00 & 0,20 \\
\hline 1997 & 0,50 & 0,25 & 0,25 \\
\hline
\end{tabular}

\section{¿Modernidad discrimina cierre?}

Existen múltiples evidencias de que sectores significativos de las ciudades grandes se han alejado del bipartidismo. ¿Ha configurado el votante urbano unas nuevas mayorías centristas y modernizadoras? La respuesta debe ser enunciada a varios niveles. Primero, en la instancia de la elección popular de alcaldes la diferencia entre las grandes ciudades y el resto del país es clara y conocemos por lo menos fragmentos importantes de lo que está sucediendo. Por ejemplo, en Bogotá los estratos altos se han ido fatigando con la «cárcel bipartidista» mientras que la clase media baja -el gran elector de la ciudad-protagonizó una evolución mucho más prudente (Gutiérrez, 1995; Botero, 1998). Segundo, como lo observó el lector en el Gráfico II, la proporción de veces en que los tradicionales resultaron absolutamente dominantes en el Concejo fue apenas

39. Por ejemplo, el asesinato de Rodrigo Turbay Cote por parte de las FARC parece haber sido producto de la manipulación de una fracción del liberalismo contra otra: Las «hienas». Semana, 424 7/07/97, 38. Dos buenos trabajos que evidencian las fluidas relaciones guerrilla clientelismo son: Peñate, Andrés. Arauca: Politics and oil in a Colombian province. Tesis de maestría de Oxford, mayo de 1991; y PALACiOS, Marco. La solución política al conflicto armado 1982-1997. En CAMACHO, Álvaro y LEAL, Francisco. Armar la paz es desarmar la guerra. Bogotá: Iepri-Fescol-Cerec, 1999, 345-402.

40. Que sepa, tampoco hay una comparación sistemática del nivel de bipartidismo de los territorios muy influidos por las FARC, el ELN, los paramilitares y, por ejemplo, las 11 ciudades más importantes del país. Aventuro una conjetura: la diferencia es sorprendentemente pequeña.

41. Una vez más, esta idea sólo debe entenderse como una «conjetura razonable», expuesta a un margen de duda también razonable. 
FRANCISCO GUTIÉRREZ SANÍN

levemente inferior en las ciudades (barras negras) que en el resto de los municipios (barras grises), pero al final del período tendió a igualarse: las ciudades se cerraron. Es decir, la hegemonía tradicional sobre los cuerpos colegiados municipales se profundizó. Hubo más rotación en las ciudades (ver Tabla IV), aunque la diferencia la colocan los municipios en los que hubo «dictadura» a lo largo de todo el período. Excluyendo estos casos extremos, las dos categorías se tornan muy similares. Tercero, a nivel nacional no parece ser posible encontrar alguna especificidad del comportamiento urbano (Pinzón, 1998), pero todavía es temprano para aventurar opiniones muy firmes.

Tabla IV: Rotación en el período para concejos de ciudades y municipios

\begin{tabular}{|c|c|c|c|}
\hline & Rotación $=0$ & Rotación $>0 \mathrm{y}=<0,5$ & Rotación $>0,5$ \\
\hline Ciudades & 0,17 & 0,5 & 0,33 \\
\hline Municipios & 0,37 & 0,54 & 0,09 \\
\hline
\end{tabular}

Usando la categorización del trabajo de Sarmiento et al. (1998) se encuentran evidencias a favor de la tesis modernizante. En la Tabla $\mathrm{V}$ se muestran los principales indicadores de cierre/apertura. Aunque rotación y dictadura se portan muy bien -un ajuste casi perfecto de la hipótesis «a mayor nivel de desarrollo mayor apertura»-, partido hegemónico es casi completamente insensible al paso de una categoría a otra. La razón es sencilla: las grandes ciudades han sido un bastión tradicional del Partido Liberal (como ha señalado Pinzón en varios trabajos, 1998). Pero esto pone en evidencia una de las debilidades centrales de la tesis de Nielson y Shugart. En lugar de crear un programa político que actúa como una «mediana en todas las direcciones», el bloque urbano, de existir, está signado por una importante inconsistencia. Por una parte, acompaña a las expresiones anticlientelistas. Por otra, tiene una larga tradición liberal, el partido mayoritario y a la vez el representante de las formas más agresivas de clientelismo y corrupción. Esto en ocasiones produce expresiones espectaculares de sincretismo político, como en Barranquilla ${ }^{42}$.

Tabla v: Indicadores de cierre para categorías de municipios (categoría 1 = la más atrasada; categoría $6=$ la más desarrollada $) /$ concejos $(\mathrm{N}=220)$

\begin{tabular}{c|c|c|c}
\hline $\begin{array}{c}\text { Categoría (N)/Variable de } \\
\text { apertura }\end{array}$ & $\begin{array}{c}\text { Rotación (promedio en el } \\
\text { período) }\end{array}$ & $\begin{array}{c}\text { Dictadura (proporción de } \\
\text { municipios con dictadura en } \\
\text { la categoría) }\end{array}$ & $\begin{array}{c}\text { Dominio tradicional } \\
\text { (proporción de veces que los } \\
\text { tradicionales tuvieron más } \\
\text { poder de voto) }\end{array}$ \\
\hline Categoría 1 (40) & 0,173 & 0,38 & 0,94 \\
\hline Categoría 2 (64) & 0,162 & 0,23 & 0,932 \\
\hline Categoría 3 (57) & 0,217 & 0,21 & 0,931 \\
\hline Categoría 4 (47) & 0,178 & 0,15 & 0,918 \\
\hline Categoría 5 (8) & 0,337 & 0 & 0,901 \\
\hline Categoría 6 (4) & 0,375 & 0 & 0,904 \\
\hline
\end{tabular}

42. El padre Bernardo Hoyos protagonizó en Barranquilla uno de los más exitosos esfuerzos renovadores en el país. En la actualidad cumple su segundo mandato como alcalde, gracias a una alianza electoral con los caciques de su ciudad (a su vez, unos de los más atrasados del país). 
Como la hipótesis que se discute supone que hay dos o más «poblaciones» (categorías de centros urbanos) con diferente comportamiento político, dos ejercicios estadísticos parecen particularmente adecuados: análisis discriminante y prueba de diferencia de medias. En la Tabla vi se presentan los resultados del segundo para un análisis «binario» (ciudades vs. municipios). La imagen que aparece al intentar interpretar estos ejercicios de correlación es extremadamente interesante. En las ciudades no se produce «dictadura local», y hay más rotación. La adhesión al partido mayoritario (quintil 3) también produce diferencias estadísticamente significativas entre las dos categorías, pues las ciudades son más liberales que los municipios. Desde el punto de vista de dominio tradicional, existencia de fuerza hegemónica y partido efectivo en las votaciones para cuerpo colegiado el comportamiento es similar. En cambio, partido efectivo en las tres elecciones para alcalde sí discrimina entre uno y otro grupo. Agrupando todas estas conclusiones, se puede ver que sólo la combinación modernidad-elecciones para Ejecutivo parece producir comportamientos que favorecen a las terceras fuerzas. Los mismos electores que aúpan a los nuevos a las alcaldías se tornan prudentes a la hora de escoger a sus congresistas, concejales y ediles ${ }^{43}$. En presencia de este síndrome, no extraña que los renovadores sean en Colombia furiosamente antiparlamentarios y críticos implacables de los cuerpos colegiados a todos los niveles.

Tabla vi: Prueba de diferencias de medias

\begin{tabular}{l|l}
\hline Indicador «binario» (ciudades vs. municipios) & $\begin{array}{l}\text { Mean Difference Test (significación 0,05) } \\
\text { [valor p univariado] }\end{array}$ \\
\hline Dictadura & Rechazar hipótesis nula $[0,029]$ \\
\hline Rotación & Rechazar hipótesis nula $[0,029]$ \\
\hline Quintil 3 & $\begin{array}{l}\text { Rechazar hipótesis nula }[0,01]->\text { media urbana } 0,34, \text { media } \\
\text { municipal } 0,52\end{array}$ \\
\hline Dominio tradicional & No se puede rechazar la hipótesis nula $[0,4]$ \\
\hline Hegemonía & No se puede rechazar la hipótesis nula $[0,09]$ \\
\hline Partido efectivo/Concejo 1992 & No se puede rechazar la hipótesis nula $[0,086]$ \\
\hline Partido efectivo/Concejo 1994 & No se puede rechazar la hipótesis nula $[0,06]$ \\
\hline Partido efectivo/Concejo 1997 & No se puede rechazar la hipótesis nula $[0,1]$ \\
\hline Partido efectivo/alcalde $1992^{44}$ & Rechazar hipótesis nula [0,0002] \\
\hline Partido efectivo/alcalde $1997^{45}$ & Rechazar hipótesis nula $[0,001]$ \\
\hline
\end{tabular}

\section{¿Dictadura social?}

El Congreso colombiano es una corporación bastante reaccionaria, y varias de las reformas fundamentales del país han encallado allí. Respecto de la clase política colombiana, empero, más que estancamiento lo que parece haberse producido es

43. Esto, por supuesto, podría ser temporal y terminar derivando en un voto consistentemente antitradicional.

44. Faltan los datos de partido efectivo para las elecciones de alcalde en Bogotá en 1994.

45. Número de municipios $=198$ (para los otros no hay datos). 
una «democratización traumática». Hay todavía muy pocos trabajos sistemáticos sobre el tema, pero ya se pueden aventurar algunas conjeturas.

En las últimas dos décadas se produjo un fenómeno masivo de movilidad social ascendente, que cohabitó por lo menos durante la década de los 90 con un aumento de la desigualdad agregada. Aquella movilidad tuvo dos grandes dinamizadores, la economía ilegal y la ampliación del cubrimiento educativo en todos sus niveles. Estudios específicos de redes clientelistas (Gutiérrez, 1998a) tienden a mostrar que ambos, ilegalidad y educación, encontraron lugar en el sistema político ${ }^{46}$ y, gracias a la desinstitucionalización de los partidos tradicionales, protagonizaron una renovación que desplazó parcialmente a los notablatos tradicionales que tenían bajo su férreo dominio la política local. Los notablatos perdieron su monopolio económico, cognitivo (manejo de la sociotécnica jurídica) y electoral (las redes clientelistas se fraccionaron más y más, y en la medida en que el elector se independizaba lo hacían los escalones inferiores de las redes en su relación con los superiores $)^{47}$. El nuevo protagonista sería una alianza inestable y heterogénea de fuerzas sociales insurgentes: letrados de primera generación, contrabandistas y narcos, apparátchiki del bipartidismo reciclados que se descubrieron rebeldes, y redes de parentesco y solidaridad. Pequeños caciques de barrio y vereda, que en el pasado sólo podían soñar con el papel de comparsas, hallaron el camino al Concejo, la Asamblea e incluso al Congreso (Gutiérrez, 1996). Esto desquició al sistema al menos en tres formas distintas. Antes que nada, rompió los acuerdos entre las elites y bloqueó la renovación de los pactos consociacionales. En la medida en que el partido liberal fue quien mejor expresó los intereses de estas alianzas -con su ethos simultáneamente plebeyo, antioligárquico y profundamente conservador-, quedó prisionero de un auditorio que por necesidad lo enfrentaría a sectores importantes, y dominantes, de la sociedad colombiana. Segundo, produjo un serio desencuentro entre la tecnocracia gubernamental, las elites económicas y la opinión pública, por un lado, y la clase política, por otro. La insatisfacción creciente de los primeros con respecto del comportamiento errático de los segundos generó un hiato entre representación (maquinaria partidista) y presentación (capacidad de dialogar con el mundo moderno y los medios). La cuadratura del círculo para casi todos los candidatos -desde el que aspira a la alcaldía del municipio más humilde hasta el que se postula para presidente- es combinar «opinión»y «maquinaria». Tercero, cambió los términos del discurso político, en la medida en que junto con los renovadores provenientes de otras vertientes aparecieron los renovadores liberales. Estos últimos protestaban contra los bloqueos del sistema, que les estorbaba el camino del ascenso social y los castigaba por ser advenedizos.

En síntesis, la composición de clase de los cuerpos colegiados debe haber cambiado significativamente, aunque esto sólo lo puedo aventurar como conjetura puesto que al parecer no hay estudios sistemáticos sobre el tema. La fuerza política mayoritaria

46. Hay universidades privadas para la clase media baja cuyas carreras de Derecho, por ejemplo, se han convertido en la alternativa educativa para los políticos.

47. La estrategia municipalista de los grupos armados ilegales también dificultó a los notablatos tradicionales usar a las Fuerzas Armadas como una guardia pretoriana para defender sus intereses. 
expresa la fuerza, pero también el resentimiento, del ascenso social frustrado. A la inversa, el esfuerzo de aconductamiento legal transita por las vías del Estado de derecho pero también, a veces de manera muy deliberada, por las de la exclusión de los advenedizos. Nunca antes las elites habían estado tan divididas, entre sí y en su relación con las fuerzas tradicionales. El sistema político se ha mostrado incapaz de promover inclusiones legales (esto es, ciudadanas), pero expresa espontáneamente las inclusiones ilegales.

\section{Conclusiones}

Después de este recorrido, ¿estamos mejor capacitados para contestar a la pregunta de si se ha abierto o no el sistema político? Creo que sí. La respuesta es sencilla: se ha abierto y cerrado simultáneamente. Mi impresión es que nos hallamos en el cruce de múltiples cierres y aperturas que configuran una trampa en [al menos] cuatro dimensiones.

- Primera: Por un lado, el período está atravesado por aperturas institucionales que, si bien son gradualistas, no pueden reducirse a lo cosmético sino a un esfuerzo desmedido de la imaginación ${ }^{48}$. Si se quisiera hablar de relegitimación de las instituciones, habría material para ello (comenzando por una participación electoral creciente). Por otro lado, encontramos una profundización de las exclusiones extrainstitucionales, cada vez más intensas, indiscriminadas y terroristas (y dirigidas no sólo contra opositores políticos sino contra activistas sociales).

- Segunda: En relación con lo anterior, por un lado, la década de los 90 contempló un esfuerzo importante por desterrar la «informalidad democrática», es decir, la articulación de las instituciones convencionales con la ilegalidad (incluyendo allî las modalidades irregulares de la estrategia antiinsurgente). Se buscó fortalecer el Estado de derecho, recuperar algunos de los monopolios fundamentales del Estado y ajustarse a las agendas internacionales postcaída del muro. Por otro lado, la informalidad se fortaleció por dos vías: a) el crecimiento desaforado del terror; b) la capacidad de los tradicionales de apoyar ese terror y, simultáneamente, de expresar las reinvindicaciones de bases sociales involucradas en procesos de movilidad ascendente o afectadas severamente por procesos masivos de ilegalización (Ramírez, 1996, habla de un «campesinado ilícito»; Palacios, 1995, de «ciudad ilegal»). Nota bene, es posible comprender bien algunos de los efectos distorsionadores del terror sobre el sistema, pero eso no explica automáticamente las mayorías tradicionales. Algo similar se puede afirmar con respecto de la corrupción.

48. Dos parámetros se han mantenido constantes, presidencialismo y sistema electoral proporcional. Habría que estudiar cómo las constantes institucionales interactúan con las variables a lo largo del período, pero ese esfuerzo escapa al foco de atención de este texto. 
- Tercera: Por un lado, cada vez se oyen más voces (más grupos alcanzan a ser elegidos, y adquieren visibilidad con su acción política). Por otro, el poder efectivo de voto de los nuevos sigue siendo mínimo y no ha evolucionado positivamente en todo el período. De hecho, en algunos casos podría haber disminuido (esto es lo que ha pasado en el Congreso). En cierto sentido, hemos pasado de bipartidismo a multipartidismo. En otro, de bipartidismo a un sistema de «partido y medio», con la pérdida de pie del Partido Conservador y la desinstitucionalización progresiva de los tradicionales. Es verdad que después del bache de los 80 hubo un repunte en la década de los 90 . Esto demuestra que en Colombia los cambios sí sirven, pero que la constante de proporcionalidad que relaciona magnitud del cambio institucional y resultados electorales es muy, muy pequeña ( $\sin$ descontar los efectos laterales indeseados).

- Cuarta: Modernidad no discrimina comportamiento político si no se usa un criterio adicional, esto es, elecciones ejecutivas vs. legislativas. Las ejecutivas, sobre todo elección popular de alcaldes, son el nicho de oportunidad de los nuevos ${ }^{49}$. Los nuevos son una esperanza en la medida en que se presentan como la fuerza incluyente. A la vez, buena parte de ellos tienen todas las razones, tanto estéticas, morales y políticas como estratégicas (conveniencia) para deplorar a los cuerpos colegiados y al Parlamento. Son incluyentes, pero están tentados por las vías semidemocráticas. Lejos de constituir un centro estabilizador, presentan una oportunidad pero también un peligro. Al mismo tiempo modernizadores y antiparlamentarios, podrían protagonizar una peligrosa deriva autoritaria. En esto, Colombia no hace sino seguir, a su manera, una tendencia general de todo el área andina $a^{50}$.

A propósito, esto sugiere que la búsqueda de un balance entre conocimiento detallado de cada caso y cuantificación/análisis institucional podría ayudar a desarrollar formatos más cómodos para el ejercicio comparativo. Me refiero a argumentos y narrativas capaces de captar las sutilezas de cada país, pero a la vez de ofrecer paisajes lo suficientemente bien delineados como para que sean contrastables.

49. Pero también aparentemente las presidenciales; tenemos buenas evidencias a favor de esta afirmación, pero no resultados sistemáticos.

50. En Colombia hay una complicación adicional: la combinación de particularismo y policlasismo que da a los tradicionales una gran eficacia electoral. Los nuevos han tendido a renunciar al policlasismo, y esto genera múltiples tensiones. El tema escapa a los límites de este artículo. 
FRANCISCO GUTIÉRREZ SANÍN ¿SE HA ABIERTO EL SISTEMA POLÍTICO COLOMBIANO? UNA EVALUACIÓN DE LOS PROCESOS DE CAMBIO (1970-1998)

\section{Bibliografía}

Bond, D.; Craig, J.; JENKIns, Ch.; TAYLOR y SCHOCK, K. Mapping mass political conflict and civil society. Issues and prospects for the automated development of event data. Journal of Conflict Resolution, 1997, vol. 41, n." 4, 553-579.

Botero, Camila. Las elecciones en Bogotá. En Bejarano, Ana María y DÁvila, Andrés (comps.). Elecciones y democracia 1997-1998. Bogotá: Fundación Social, D. de Ciencias Políticas Universidad de los Andes, Veeduría Ciudadana, 1998, pp. 141-190.

Felsenthal, Dan y Machover, Moshé. The measurement of voting power. Theory and practice, problems and paradoxes. UK: Edward Elgar Publishing, 1998.

GuTIÉRREZ, Francisco. La ciudad representada. Politica y conflicto en Bogotá. Bogotá: Iepri-Tercer Mundo, 1998a.

- Rescate por un elefante: Congreso, sistema y reforma política. En BEJARANO, Ana María y DÁvilA, Andrés (comps.). Elecciones y democracia 1997-1.998. Bogotá: Fundación Social, D. de Ciencias Políticas Universidad de los Andes, Veeduría Ciudadana, 1998b, pp. 215-253.

- Dilemas y paradojas de la transición participativa. Análisis político, 1996, n. ${ }^{\circ} 29,35-53$.

- Tendencias de cambio en el sistema de partidos: el caso de Bogotá. Análisis político, 1995, n. ${ }^{\circ} 24,73-83$.

HARTLYN, Jonathan. La política del régimen de coalición. La experiencia del Frente Nacional en Colombia. Bogotá: CEI, Uniandes, Tercer Mundo, 1993.

Hinich, Melvin y Munger, Michael. Analytical politics. Cambridge: Cambridge University Press, 1997.

Hungtinton, Samuel. El orden político en las sociedades en cambio. Buenos Aires: Paidós, 1972.

KraIN, Matthew. Contemporary democracies revisited. Democracy, political violence and event count models. Comparative Political Studies, 1998, vol. 31 n. ${ }^{\circ}$ 2, 139-164.

LEAL, Francisco. Estado y política en Colombia. Bogotá: Siglo XXI, 1984.

LEAL, Francisco y DÁvILA, Andrés. Clientelismo, el sistema político y su expresión regional. Bogotá: Iepri-Tercer Mundo, 1991.

López Michelsen, Alfonso. La operación avispa. El Tiempo, 1998, 13 de febrero, 3 A.

Martínez BenCARdino, Ciro. Muestreo. Algunos métodos y sus aplicaciones prácticas. Bogotá: Ecoe, 1984

MARTZ, John. The politics of clientelism. New Jersey: Transaction Publishers, New Brunswick, 1997.

NiElson, Daniel y SHugart, Matthew. Constitutional change in Colombia. Policy adjustment through institutional reform. Comparative Political Studies, 1999, vol. 32, n. ${ }^{\circ} 3,313-332$.

PalaCios, Marco. Entre la legitimidad y la violencia. Colombia (1975-1994). Bogotá: Norma, 1995.

PIZARRO, Eduardo. ¿Hacia una salida democrática de la crisis nacional? En CÁRDENAS, Miguel (ed.). Modernidad y sociedad política en Colombia. Bogotá, 1993.

- Democracia restringida y desinstitucionalización política. En MEdELlín, Pedro (comp.). La reforma del Estado en América Latina. Bogotá: Fescol, 1989.

Pizón, Patricia. Una aproximación al voto urbano: el voto en las ciudades colombianas. En Bejarano, Ana María y DÁvila, Andrés (comps.). Elecciones y democracia 1997-1998. Bogotá: Fundación Social, D. de Ciencias Políticas Universidad de los Andes, Veeduría Ciudadana, 1998, pp. 401-432.

Powell, G. Bingham. Contemporary democracies. Participation, stability and violence. Cambridge and London: Harvard University Press, 1982. 
Querubín, Cristina; SÁNCHEZ, María Fernanda y Kure Ileana. Dinámica de las elecciones populares de alcaldes, 1988-1997. En Bejarano, Ana María y DÁvila, Andrés (comps.). Elecciones y democracia 1997-1998. Bogotá: Fundación Social, D. de Ciencias Políticas Universidad de los Andes, Veeduría Ciudadana, 1998, pp. 141-190.

Ramírez T., William. ¿Un campesinado ilícito? Análisis Político, 1996, n. ${ }^{\circ}$ 29, 54-62.

- Estado, violencia y democracia. Bogotá: Tercer Mundo Editores, 1990.

REYES, Alejandro. Latifundio y poder político: la bacienda ganadera en Sucre. Bogotá: Cinep, 1978.

SARMIENTO, Libardo (director de la investigación). Municipios y regiones de Colombia. Una mirada desde la sociedad civil. Bogotá: Fundación Social, 1978.

TAYLOR, Alan. Mathematics and politics. Strategy, voting, power and proof. New York, Berlin, Heidelberg, London, Paris, Tokyo, Hong Kong, Barcelona, Budapest: Springer Verlag, 1995. 